\title{
Cognitively oriented psychotherapy for early psychosis (COPE): A 1-year follow-up
}

\author{
Henry Jackson, * Pat McGorry, Lisa Henry, Jane Edwards, Carol Hulbert, \\ Susy Harrigan, Paul Dudgeon, Shona Francey, Dana Maude, John Cocks and \\ Paddy Power \\ Early Psychosis Prevention and Intervention Centre (EPPIC) and the Departments of Psychology and Psychiatry, \\ University of Melbourne, Australia
}

Objectives. Cognitively oriented psychotherapy for early psychosis (COPE) is aimed at facilitating the adjustment of the person, and at preventing or alleviating secondary morbidity in the wake of the first psychotic episode.

Design. A total of 80 people participated in the initial trial and completed assessments on a range of outcome measures. Post-treatment assessment results from a non-randomized controlled trial of COPE have been previously reported. The present paper describes the results obtained from 51 patients who attended a followup assessment 1 year subsequent to the end-of-treatment assessment.

Method. The 51 patients formed three groups: (1) those who were offered and accepted COPE; (2) those who were offered COPE but refused it, and continued to receive other services from the Early Psychosis Prevention and Intervention Centre (EPPIC) (refusal subjects); and (3) those who were offered neither COPE nor any other continuing treatment from EPPIC (control subjects).

Results. At 1-year follow-up, there was only one significant difference and this was between the COPE and refusal groups on the Integration/Sealing Over (I/SO) measure $(p=.008)$. End-of-treatment differences were mostly sustained over the 1year follow-up period. When the complete sample of 80 was considered, there were no differences between the three groups in terms of hospital admissions, community episodes, or time taken to first in-patient re-admission.

Conclusions. The study was weakened by the poor follow-up rates in the two control groups. This reduced power to detect differences between groups on the seven major measures. However, the relapse data gathered on the complete set of 80 patients were discouraging and suggest that the present formulation of COPE does not confer any advantage to those patients receiving the therapy over those not receiving the therapy.

\footnotetext{
* Requests for reprints should be addressed to Professor Henry Jackson, Department of Psychology, School of Behavioural Science, University of Melbourne, Parkville, 3052, Victoria, Australia (e-mail: H.Jackson@ psych.unimelb.edu.au).
} 
In an initial report (Jackson, McGorry, Edwards, \& Hulbert, 1996) we described our attempt to develop a new approach to psychotherapy for patients in this phase of illness. This therapy, known as cognitively oriented psychotherapy for early psychosis or COPE, is specifically focused on the adjustment of individuals recovering from their first episode of psychosis. Primarily, COPE aims to help the person resume their developmental tasks (e.g. career, relationships, develop a sense of identity). A second aim is of alleviating or prophylactically inhibiting the development of secondary morbidity (e.g. depression, social anxiety). Unlike research emanating from the UK (Bentall, Haddock, \& Slade, 1994; Chadwick \& Birchwood, 1994; Chadwick, Birchwood, \& Trower, 1996; Drury, Birchwood, Cochrane, \& Macmillan, 1996; Fowler, Garety, \& Kuipers, 1995; Garety et al., 1997; Kingdon \& Turkington, 1994; Kuipers et al., 1997; Tarrier, 1992; Tarrier et al., 1998), we did not focus on the positive symptoms of psychosis. This is because the vast majority (approximately 80-90\%) of first-episode patients achieve an early remission of positive symptoms as a result of increasingly effective and better tolerated medications (Edwards, Maude, McGorry, Harrigan, \& Cocks, 1998; Lieberman et al., 1993; Power et al., 1998).

The theoretical background and description of the therapy are outlined elsewhere (Jackson et al., 1996) and detailed more recently in Jackson, Edwards, Hulbert, and McGorry (1999). Briefly, COPE therapy consists of four phases. The first is an assessment phase in which there is a focus not only on understanding the emergence and severity of positive and negative symptoms but their impact on the person's sense of life direction, goals, and aspirations. Also, we are interested in understanding and working with the patient's explanatory model for the 'illness'. The second phase is the engagement phase in which the focus is on establishing a working alliance with the patient. The third phase focuses on issues of adaptation where we examine the impact of the psychosis on the person's psychology. Further, we help the patient to take stock of their psychological resources, examine the cognitive 'roadblocks' to the person resuming their career, aspirations, social life and so forth, build up coping skills, and help the patient implement behavioural activities to reconnect with their various life domains, e.g. contacting their previous employer. The final phase is where we focus on treating secondary morbidity such as social anxiety, depression, panic attacks, and post-traumatic stress disorder. Cognitive-behavioural techniques are of key importance in the latter two phases (Jackson et al., 1999).

We tested this therapy in a preliminary way in a controlled but non-randomized trial (Jackson et al., 1998) which examined differences at the conclusion of treatment between three groups on seven measures and reported data on relapses. The first of the three groups included those patients who received the range of treatment services from the Early Psychosis Prevention and Intervention Centre (EPPIC: McGorry, Edwards, Mihalopoulos, Harrigan, \& Jackson, 1996) and were offered and accepted COPE (COPE group). The second group consisted of those patients who received the range of treatment services from EPPIC, and were offered, but refused COPE (refusal group). The third group of patients consisted of those patients who received in-patient services from EPPIC but belonged to geographic regions other than the region served by EPPIC; they received no further treatment services from EPPIC once they were discharged from the EPPIC in-patient service (control group). At the end of treatment, the results described briefly here, were that for four of the seven measures, significant differences existed 
between the COPE and the control group. However, there was only one significant difference between the COPE and refusal groups, that being on the Integration/Sealing Over $(\mathrm{I} / \mathrm{SO})$ measure. There were no significant differences between the three groups on two other measures (BPRS and GSI of the SCL-90-R); however, there was an interesting and strong trend towards significance on the SANS measure $(p=.06)$. On the seventh measure-the BDI-there was a significant finding but one that favoured the refusal group over the COPE group $(p<.05)$.

The empirical demonstration of the durability of treatment gains is an important matter for patients, clinicians and mental health administrators alike. The emphasis on evidence-based treatments highlights the importance of this in a range of domains in clinical psychology and psychiatry (Nathan \& Gorman, 1998; Roth \& Fonagy, 1996). This is not to negate the importance of short-term treatment efficacy, that is, demonstrating that treatments of whatever complexion can produce improvements in the short term whilst treatment is still in effect. But of critical importance is whether treatment effects can be maintained in the absence of treatment. This paper reports data on the 1-year follow-up of the original COPE trial (Jackson et al., 1998) in the absence of further COPE treatment.

\section{Method}

\section{The sample}

Eighty patients completed the initial pilot study. Fifty-one patients consented to assessment at 1-year follow-up and not one received any further COPE treatment in the 1-year period from the conclusion of treatment to the 1-year follow-up assessment. The reasons for the 29 patients not attending follow-up were that: one was deceased (3.4\%), 17 were lost to follow-up and could not be contacted (58.6\%) and 11 refused to undergo the 12-month follow-up assessment $(37.9 \%)$. The person who died was in the refusal group and their death was deemed to be due to a workplace injury (the coroner's report was sighted) and not to suicide. Thirty-four of the 44 patients who enrolled in the COPE group participated in the followup assessment, that is, $77.3 \%$ of the initial COPE group. Conversely, only nine of the 21 refusal patients (42.9\%) returned for the 12-month follow-up, with eight out of the 15 control patients $(53.3 \%$ ) returning for the 12-month assessment. A chi-square analysis testing for differences in those proportions was significant $\left(\chi^{2}(2)=8.15, p=.02\right)$.

Inclusionlexclusion criteria. To be eligible for inclusion in the study, patients had to: be aged between 16 and 30 years; be suffering from a first episode of psychosis; and possess fluency in English. Patients were excluded if: there was an organic cause for their psychosis (e.g. a cerebral tumour revealed on MRI scan); there was evidence of low IQ (below 70); and they were diagnosed with substance dependence (not substance misuse). These criteria applied to all three groups of patients included in this study.

The patients in the control group represented people who were residing for a short period of time within the EPPIC catchment area, or were visiting someone within the EPPIC catchment area, at the time of their referral to EPPIC for in-patient treatment. On their discharge from EPPIC, such patients returned to live at their substantive address, typically the family home, but based in a geographic region not served by EPPIC. They were therefore, not eligible for continuing care from EPPIC, and in turn not eligible for COPE.

\section{Measures}

Demographics. A number of demographic and illness-related variables were recorded. They included: age, sex, marital status, education (secondary only vs. some tertiary), diagnosis, age of onset of illness, length 
of illness, length of hospitalization, and average daily dose of antipsychotic medication (in chlorpromazine equivalents).

Diagnoses. These were obtained from the Royal Park Multidiagnostic Instrument for Psychosis (RPMIP: McGorry, Copolov, \& Singh, 1990; McGorry et al., 1990). This is a semi-structured interview which uses strict decision rules to provide diagnoses according to various nosologies, although in the present study we reported only the DSM-III-R diagnoses (American Psychiatric Association, 1987).

'Psychological measures. Two were utilized. These were the Explanatory Model Scale (EM: modified from Kleinman, 1980), and the Integration/Sealing Over measure (McGlashan, Wadeson, \& Carpenter, 1977). The Integration/Sealing Over measure (I/SO: McGlashan et al., 1977) was developed as a 6-point Likert scale with end-points 'sealing over' and 'integration' being descriptions of distinct recovery styles from schizophrenia and other psychiatric disorders. It is seen to be a measure of the person's adaptation to the illness. Higher scores indicate poorer performances (e.g. more 'sealing over'). The psychometric properties of the I/SO have not been investigated.

The EM (Chanen, 1987) records a patient's understanding and beliefs about his or her illness including aetiology, time and mode of onset of symptoms, pathology, course of illness and treatment. The questionnaire uses a $0-4$ scale to rate disparities between the patient's and case manager's models of the episode of illness. Higher scores indicate greater discrepancies between the patient's and case manager's EMs (e.g. poorer insight). Kleinman (1980) did not report on the psychometric properties for his original measure which used a 0-2 scale. Kleinman (1980) did suggest better discrimination would be obtained with a 0-4 scale. Chanen (1987) took up this suggestion and using Pearson's $r$, reported inter-rater reliabilities of .87 and .81 , on each of two occasions, respectively. To the best of our knowledge no other psychometric data for the EM exist.

'Primary' symptom measures. Those used in the study were the Brief Psychiatric Rating Scale (BPRS: Overall \& Gorham, 1962; see also McGorry, Goodwin, \& Stuart, 1988, as we used their Revised Nursing Version), and the Schedule for the Assessment of Negative Symptoms (SANS: Andreasen, 1983). In this paper we only report the total scores for those two scales. Secondary morbidity measures utilized in this study were the 13-item Beck Depression Inventory (BDI: Beck \& Beck, 1972) and the General Symptom Index (GSI) of the SCL-90-R (Derogatis, 1977, 1983). The adjustment measure employed was The Quality of Life Scale (QLS: Heinrichs, Hanlon, \& Carpenter, 1984), this being a 21-item scale based on a semistructured interview originally designed to assess the deficit state in schizophrenia, but which in effect produces a measure of interpersonal and role functioning. We report only the total score in this paper. For all of the aforementioned 'primary' symptom measures, psychometric properties are reported as adequate or better (Andreasen, 1983; Beck \& Beck, 1972; Derogatis, 1977, 1983; Heinrichs et al., 1984; McGorry et al., 1988; Overall \& Gorham, 1962).

\section{Procedure}

Therapy procedure. The six therapists consisted of two consultant psychiatrists and four clinical psychologists. All therapists received weekly individual supervision with either HJ, PM, JE or $\mathrm{CH}$ as well as peer supervision-this also occurred on a weekly basis. The COPE therapist was an 'auxillary therapist' in the treating team, but was never the treating medical doctor or case manager for the person they were treating with COPE. Of the $34 \mathrm{COPE}$ patients who completed the 1-year follow-up assessment, 14 were treated by one therapist, whilst 12, 2, 2, 2, and 2, were treated by the remaining five therapists, respectively.

Patients could only be offered COPE if first, they were residents of the catchment area served by EPPIC and secondly, if they met the criteria for entry into EPPIC. One of the six therapists tracked all eligible patients once accepted into EPPIC. Patients were typically offered COPE 4-6 weeks after entry into EPPIC. By this stage, patients were typically out-patients, considered 'settled', and their positive symptoms had attenuated somewhat. The decision to begin therapy was a mutual clinical decision of both the COPE therapist and the patient's case manager. Therapy sessions were approximately 40 minutes in duration and were conducted on a flexible basis with the sessions being held once a week or 
once a fortnight. The frequency of sessions depended very much on the patient's mental state, phase of recovery and availability.

COPE consists of four phases: Engagement, Assessment, Adaptation, and Secondary Morbidity. The usual practice is for the therapist to spend the initial three to four sessions assessing the patient and engaging with the patient. An agenda or contract is arrived at through the collaborative process, usually by session 4 (Engagement and Assessment phases). This agenda forms a platform for the remainder of the therapy that targets issues of adaptation and secondary morbidity. Usually, the COPE agenda would include psychoeducation, stigma and identity issues, and problems with motivation and confidence. These issues are dealt with within a cognitive behavioural framework. Techniques were accessed from this theoretical framework and others were developed in order to form the first complete draft of the COPE manual. This occurred in conjunction with the therapist and supervisors. A fuller outline of our approach is to be found in Jackson et al. (1996, 1999). It needs to be emphasized that although the four phases of COPE are laid out here as sequential phases, this is for descriptive purposes only. Therapists (and patients) do not necessarily move through all phases in a fixed order. For example, work conducted under the rubric of Secondary Morbidity might necessitate further assessment.

We found that for the 34 COPE patients who returned for follow-up assessment, the number of sessions attended during the treatment phase ranged from 2 to 40 , there being a mean of 20.1 sessions, a SD of 12.8 , and a median of 21.5 sessions. The group of 10 COPE patients who did not return for followup assessment received a mean of 11.1 sessions, with $\mathrm{SD}=13.1$; median $=5.0$, and a range of 2-39 sessions. This difference between the two COPE subgroups approached significance $(p=.06)$ indicating that compared to the COPE follow-up non-attenders, the COPE patients who completed the 1-year follow-up assessment had attended more COPE sessions during the 'active' therapy phase, and therefore appeared more engaged in the therapy.

Procedure for assessments. In this paper we report data for three assessment points labelled as pre-treatment (or baseline), end-of-treatment (or post-treatment), and follow-up (this being 1-year post-treatment), respectively. Assessments for the instruments listed above were conducted by one of four research assistants, each of whom had the minimum of a 4-year BA (Hons) degree. All had undergone extensive training in psychopathology and on the various instruments involved in this study, as well as in other studies. Also, all four raters had obtained extensive experience in rating psychopathology in psychotic patients.

\section{Results}

\section{Demographic and illness characteristics}

The demographic and illness characteristics of the three groups are set out in Table 1. Using $2 \times 2$ ANOVAs (with the two main effects being group status and follow-up attender status, and the interaction effect referring to the interaction between the two), no significant differences were found for age, age of onset of illness, length of psychosis (treated and untreated) and length of hospitalization $(p>.10)$. There was a significant main effect for average dose of neuroleptics $(p=.003)$ and, as can be seen from Table 1 , patients on higher doses of medication did not return for follow-up assessment. There were no group or interaction effects for this latter variable $(p>.10)$. Parenthetically, it should be noted that for the three variables of length of psychosis, length of hospitalization, and average dose of neuroleptics, log transformations were necessary to correct successfully for the degree of skewness. However, even when these three variables were left untransformed, Kruskal-Wallis and Mann-Whitney tests yielded the same results. In fact, once again, the only significant result was for the 1-year follow-up nonattenders to be on higher doses of neuroleptics (Mann-Whitney $U=367.51, p=.004$ ).

An initial series of four chi-squares failed to detect main effect differences between follow-up attenders $(N=51)$ and non-attenders $(N=29)$ for the four variables of 
gender, diagnosis, marital status and education $(p>.30)$. A second set of 12 chisquares involved a comparison of attenders versus non-attenders within each of the three groups (total $N=80$ ). There were no significant differences within the three groups for gender, diagnosis, or marital status $(p>.26)$. For education, there were no significant differences within COPE or the refusal group $(p>.20)$, but there was a trend for the control group $(p=.07)$ showing that within the control group, those patients who attended the 1-year follow-up assessment were more likely to have some tertiary education. A third series of four chi-squares were run for the same four variables of gender, diagnosis, marital status and education, to determine differences between the three groups for those who attended the 1-year follow-up (total $N=51$ ). No significant differences were found between the three groups for gender, diagnosis, and marital status $(p>.26)$. There was a significant result for education $(p=.005)$. The refusal group contained significantly more patients with up to secondary education than would be expected by chance. Conversely, there were significantly more patients with some tertiary education or better in the control group.

\section{Major analyses}

We examined for differences between the three groups at the end-of-treatment and 12 months from the completion of COPE treatment, the latter constituting 1-year followup in the absence of any further COPE treatment. Table 2 displays the unadjusted means and standard deviations for both the follow-up attenders and non-attenders (note that the latter failed to complete the 1-year assessment), within each of the three groups, for the seven primary outcome variables over the three time points of pre-treatment, end-of-treatment, and 12-month follow-up. Sample sizes ranged from 73 for the GSI to 80 for the BPRS and QLS for the total sample at the end of treatment, and from 44 for the GSI to 51 for the BPRS and QLS for the follow-up attender only analyses.

\section{Follow-up attender only analyses $(N=51)$}

With the exception of the QLS-where ANOVA and planned contrasts were used, ANCOVAs (controlling for pre-treatment scores) and planned contrasts were used to detect between-group differences on the primary measures at follow-up. There was one significant difference; for the I/SO measure, $p=.03$, and planned contrasts showed that the COPE group exhibited a significantly lower I/SO score (i.e. more integrated) than the refusal group $(p=.008)$. Differences between the three groups for the remaining six measures were non-significant $(p>.10)$.

Changes between end-of-treatment and follow-up were analysed (with maximum $N=51$ ) using within-group $t$ tests. The COPE group deteriorated significantly and by an average of 3 points on the BPRS measure $(p=.03)$, and there was a trend towards significant deterioration within the refusal group on the $\operatorname{EM}(p=.09)$ and the QLS $(p=.06)$. All other within-group comparisons were non-significant $(p>.10)$.

Ancillary analyses: examination of the interaction between attender status and treatment condition Ancillary analyses were conducted to investigate whether the 29 follow-up nonattenders might have differentially influenced the results. Inspection of Table 2 reveals 
Table 1. Means (and standard deviations) or frequencies, for demographic and illnessrelated variables for the follow-up attenders and non-attenders within the three groups

\begin{tabular}{|c|c|c|c|}
\hline Variables & COPE & Refusal & Control \\
\hline \multicolumn{4}{|l|}{ Gender (m:f) } \\
\hline Attenders & $18: 16$ & $7: 2$ & $6: 2$ \\
\hline Non-attenders & $6: 4$ & $9: 3$ & $5: 2$ \\
\hline \multicolumn{4}{|l|}{ Age, years } \\
\hline Attenders & $21.47(3.47)$ & $21.11(3.37)$ & $22.63(3.34)$ \\
\hline Non-attenders & $21.10(2.77)$ & $20.83(3.27)$ & $21.14(4.30)$ \\
\hline \multicolumn{4}{|c|}{$\begin{array}{l}\text { Education (secondary school: tertiary } \\
\text { education) }\end{array}$} \\
\hline Attenders & $22: 12$ & $9: 0$ & $2: 6$ \\
\hline Non-attenders & $6: 4$ & $10: 2$ & $5: 2$ \\
\hline \multicolumn{4}{|c|}{ Marital status (number never married) } \\
\hline Attenders & 30 & 9 & 7 \\
\hline Non-attenders & 10 & 11 & 7 \\
\hline \multicolumn{4}{|l|}{ Age of onset, years } \\
\hline Attenders & $21.03(3.54)$ & $20.11(2.20)$ & $22.50(3.25)$ \\
\hline Non-attenders & $20.90(2.92)$ & $20.33(3.37)$ & $20.86(4.30)$ \\
\hline \multicolumn{4}{|c|}{$\begin{array}{l}\text { Length of psychosis (treated and untreated) } \\
\text { in days }{ }^{a}\end{array}$} \\
\hline Attenders & $202(234)$ & $405(1081)$ & $76(96)$ \\
\hline Non-attenders & $131(107)$ & 247 & $109(87)$ \\
\hline \multicolumn{4}{|c|}{ Length of hospitalization, days ${ }^{a}$} \\
\hline Attenders & $57(76)$ & $43(39)$ & $27(13)$ \\
\hline Non-attenders & $54(24)$ & $37(21)$ & $52(26)$ \\
\hline \multicolumn{4}{|c|}{$\begin{array}{l}\text { Average dose of neuroleptics (in } \\
\text { chlorpromazine equivalents) }\end{array}$} \\
\hline Attenders & $367(308)$ & $264(184)$ & $313(252)$ \\
\hline Non-attenders & $463(243)$ & $411(210)$ & $663(440)$ \\
\hline \multicolumn{4}{|l|}{ Diagnosis } \\
\hline \multicolumn{4}{|l|}{ Schizophrenia } \\
\hline Attenders & 14 & 3 & 3 \\
\hline Non-attenders & 4 & 6 & 2 \\
\hline \multicolumn{4}{|l|}{ Schizophreniform } \\
\hline Attenders & 6 & 3 & 0 \\
\hline Non-attenders & 1 & 3 & 0 \\
\hline \multicolumn{4}{|l|}{ Schizoaffective } \\
\hline Attenders & 3 & 0 & 1 \\
\hline Non-attenders & 1 & 1 & 1 \\
\hline \multicolumn{4}{|l|}{ Bipolar/Depressive } \\
\hline Attenders & 8 & 2 & 4 \\
\hline Non-attenders & 2 & 0 & 4 \\
\hline \multicolumn{4}{|c|}{ Delusional/Psychotic (NOS) } \\
\hline Attenders & 3 & 1 & 0 \\
\hline Non-attenders & 2 & 2 & 0 \\
\hline
\end{tabular}

${ }^{a}$ Variable was log-transformed for the data analyses. 
Table 2. Means (and standard deviations) for the follow-up attenders and non-attenders within the three groups across the three time points for the seven major measures

\begin{tabular}{|c|c|c|c|c|c|c|c|c|c|}
\hline \multirow[t]{2}{*}{ Measures } & \multicolumn{3}{|c|}{ Pre-Treatment } & \multicolumn{3}{|c|}{ End-of-Treatment } & \multicolumn{3}{|c|}{ Follow-up } \\
\hline & COPE & Refusal & Control & COPE & Refusal & Control & COPE & Refusal & Control \\
\hline \multicolumn{10}{|l|}{$\mathrm{I} / \mathrm{SO}$} \\
\hline Attenders & $\begin{array}{c}3.47 \\
(1.59)\end{array}$ & $\begin{array}{c}3.78 \\
(1.48)\end{array}$ & $\begin{array}{c}2.88 \\
(1.89)\end{array}$ & $\begin{array}{c}2.31 \\
(1.12)\end{array}$ & $\begin{array}{c}3.67 \\
(1.58)\end{array}$ & $\begin{array}{c}3.25 \\
(1.91)\end{array}$ & $\begin{array}{c}2.66 \\
(1.21)\end{array}$ & $\begin{array}{c}4.11 \\
(1.62)\end{array}$ & $\begin{array}{c}2.88 \\
(1.55)\end{array}$ \\
\hline Non-attenders & $\begin{array}{c}3.22 \\
(1.30)\end{array}$ & $\begin{array}{c}3.73 \\
(1.49)\end{array}$ & $\begin{array}{c}4.57 \\
(1.27)\end{array}$ & $\begin{array}{c}2.22 \\
(1.20)\end{array}$ & $\begin{array}{c}3.09 \\
(1.04)\end{array}$ & $\begin{array}{c}4.57 \\
(0.98)\end{array}$ & - & - & - \\
\hline \multicolumn{10}{|l|}{ EM } \\
\hline Attenders & $\begin{array}{c}1.21 \\
(0.89)\end{array}$ & $\begin{array}{c}1.36 \\
(0.65)\end{array}$ & $\begin{array}{c}1.05 \\
(0.89)\end{array}$ & $\begin{array}{c}0.95 \\
(0.72)\end{array}$ & $\begin{array}{c}1.20 \\
(0.81)\end{array}$ & $\begin{array}{c}1.28 \\
(0.90)\end{array}$ & $\begin{array}{c}1.15 \\
(0.71)\end{array}$ & $\begin{array}{c}1.60 \\
(0.94)\end{array}$ & $\begin{array}{c}1.40 \\
(0.75)\end{array}$ \\
\hline Non-attenders & $\begin{array}{c}1.16 \\
(1.17)\end{array}$ & $\begin{array}{c}1.82 \\
(1.12)\end{array}$ & $\begin{array}{c}2.51 \\
(0.90)\end{array}$ & $\begin{array}{c}0.93 \\
(0.58)\end{array}$ & $\begin{array}{c}1.24 \\
(0.74)\end{array}$ & $\begin{array}{c}2.60 \\
(0.97)\end{array}$ & - & - & - \\
\hline \multicolumn{10}{|l|}{ SANS } \\
\hline Attenders & $\begin{array}{c}17.70 \\
(16.17)\end{array}$ & $\begin{array}{c}19.78 \\
(18.93)\end{array}$ & $\begin{array}{c}12.38 \\
(13.02)\end{array}$ & $\begin{array}{c}13.42 \\
(12.40)\end{array}$ & $\begin{array}{c}24.78 \\
(17.17)\end{array}$ & $\begin{array}{c}16.25 \\
(16.09)\end{array}$ & $\begin{array}{c}16.33 \\
(13.75)\end{array}$ & $\begin{array}{c}27.56 \\
(17.99)\end{array}$ & $\begin{array}{c}15.63 \\
(19.29)\end{array}$ \\
\hline Non-attenders & $\begin{array}{l}15.80 \\
(7.93)\end{array}$ & $\begin{array}{c}16.00 \\
(12.09)\end{array}$ & $\begin{array}{c}30.43 \\
(18.79)\end{array}$ & $\begin{array}{c}11.10 \\
(10.19)\end{array}$ & $\begin{array}{c}9.82 \\
(7.03)\end{array}$ & $\begin{array}{c}30.86 \\
(17.45)\end{array}$ & - & - & - \\
\hline \multicolumn{10}{|l|}{ BPRS } \\
\hline Attenders & $\begin{array}{l}12.57 \\
(6.37)\end{array}$ & $\begin{array}{l}11.56 \\
(6.02)\end{array}$ & $\begin{array}{l}12.13 \\
(7.00)\end{array}$ & $\begin{array}{l}12.09 \\
(7.81)\end{array}$ & $\begin{array}{l}11.00 \\
(7.70)\end{array}$ & $\begin{array}{l}11.38 \\
(9.30)\end{array}$ & $\begin{array}{l}15.09 \\
(8.63)\end{array}$ & $\begin{array}{c}14.78 \\
(9.63)\end{array}$ & $\begin{array}{l}11.63 \\
(9.12)\end{array}$ \\
\hline Non-attenders & $\begin{array}{l}10.74 \\
(2.89)\end{array}$ & $\begin{array}{l}11.24 \\
(7.98)\end{array}$ & $\begin{array}{l}14.86 \\
(5.46)\end{array}$ & $\begin{array}{l}12.10 \\
(6.87)\end{array}$ & $\begin{array}{l}13.82 \\
(7.73)\end{array}$ & $\begin{array}{l}20.14 \\
(4.91)\end{array}$ & - & - & - \\
\hline \multicolumn{10}{|l|}{$\mathrm{GSI}^{a}$} \\
\hline Attenders & $\begin{array}{c}0.87 \\
(0.66)\end{array}$ & $\begin{array}{c}0.53 \\
(0.29)\end{array}$ & $\begin{array}{c}0.73 \\
(0.40)\end{array}$ & $\begin{array}{c}0.78 \\
(0.76)\end{array}$ & $\begin{array}{c}0.40 \\
(0.43)\end{array}$ & $\begin{array}{c}0.25 \\
(0.21)\end{array}$ & $\begin{array}{c}0.74 \\
(0.70)\end{array}$ & $\begin{array}{c}0.48 \\
(0.44)\end{array}$ & $\begin{array}{c}0.32 \\
(0.18)\end{array}$ \\
\hline Non-attenders & $\begin{array}{c}1.02 \\
(0.56)\end{array}$ & $\begin{array}{c}0.70 \\
(0.72)\end{array}$ & $\begin{array}{c}0.51 \\
(0.56)\end{array}$ & $\begin{array}{c}0.72 \\
(0.53)\end{array}$ & $\begin{array}{c}0.46 \\
(0.45)\end{array}$ & $\begin{array}{c}0.59 \\
(0.55)\end{array}$ & - & - & - \\
\hline \multicolumn{10}{|l|}{$\mathrm{BDI}^{a}$} \\
\hline Attenders & $\begin{array}{c}8.88 \\
(7.28)\end{array}$ & $\begin{array}{c}5.11 \\
(3.30)\end{array}$ & $\begin{array}{c}5.50 \\
(4.72)\end{array}$ & $\begin{array}{c}7.97 \\
(8.23)\end{array}$ & $\begin{array}{c}3.44 \\
(4.80)\end{array}$ & $\begin{array}{c}3.00 \\
(4.00)\end{array}$ & $\begin{array}{c}6.33 \\
(6.01)\end{array}$ & $\begin{array}{c}3.89 \\
(3.82)\end{array}$ & $\begin{array}{c}2.33 \\
(2.16)\end{array}$ \\
\hline Non-attenders & $\begin{array}{c}6.75 \\
(5.34)\end{array}$ & $\begin{array}{c}5.27 \\
(7.34)\end{array}$ & $\begin{array}{c}5.43 \\
(6.37)\end{array}$ & $\begin{array}{c}6.38 \\
(4.75)\end{array}$ & $\begin{array}{c}2.09 \\
(2.02)\end{array}$ & $\begin{array}{c}5.71 \\
(6.70)\end{array}$ & - & - & - \\
\hline \multicolumn{10}{|l|}{ QLS } \\
\hline Attenders & \multirow{2}{*}{\multicolumn{3}{|c|}{$\begin{array}{c}\text { Measure not given at } \\
\text { pre-treatment }\end{array}$}} & $\begin{array}{l}84.43 \\
(20.85)\end{array}$ & $\begin{array}{l}75.08 \\
(27.55)\end{array}$ & $\begin{array}{c}83.25 \\
(31.26)\end{array}$ & $\begin{array}{c}84.50 \\
(21.26)\end{array}$ & $\begin{array}{c}67.89 \\
(27.97)\end{array}$ & $\begin{array}{l}85.63 \\
(33.65)\end{array}$ \\
\hline Non-attenders & & & & $\begin{array}{c}92.92 \\
(22.03)\end{array}$ & $\begin{array}{c}87.58 \\
(18.11)\end{array}$ & $\begin{array}{c}57.29 \\
(26.66)\end{array}$ & - & - & - \\
\hline
\end{tabular}

a Actual data analyses are based on log-transformed data for these two variables.

that both at pre-treatment and end-of-treatment, attenders in the control group appeared to have obtained better scores on the majority of measures than the nonattenders within the control group (see especially the SANS and QLS scores). The COPE group, and to a lesser extent, the refusal group, tended to have an opposite pattern, 
albeit a much less dramatic one, with the non-attenders in both groups scoring better than the attenders on a majority of measures. A few of the comparisons between the attenders and non-attenders within the control and refusal groups reached statistical significance $(p<.05)$. (Fuller details of these analyses can be obtained by writing directly to the first author.)

\section{Relapse}

In-patient admissions and community episodes were calculated from the Victorian Psychiatric Case Registry (Burgess, Joyce, Pattison, \& Finch, 1992). This records all inpatient and community contacts for the state of Victoria, Australia. Data were analysed four ways, specifically, in terms of: (1) the number of people within each group with one or more in-patient admission(s); (2) the number of people within each group with one or more 'community episode(s)'; (3) the number of people within each group with inpatient admission(s) and/or 'community episode(s)' combined; and (4) the time taken to first in-patient admission following the end-of-treatment assessment for each of the three groups. Data for (1) to (3) are shown in Table 3. Unlike the follow-up attender analyses where data were reported for a maximum of 51 persons, for all four of the aforementioned analyses it was possible to obtain data for all 80 patients (including the one person who died during that time) over the 1-year period following the end of treatment.

(1) The number of people within each group with one or more in-patient admission(s). Notwithstanding the small cell sizes, for this variable there was no significant result for attender status $\left(\chi^{2}(2)=1.58\right.$, exact $\left.p=.55\right)$, but there was a strong trend for nonattender status with $\chi^{2}(2)=5.66$, exact $p=.06$. As regards the latter result, inspection of the adjusted residuals found a significantly lower proportion $(16.7 \%)$ of those in the refusal group, who failed to attend 1-year follow up, were likely to be admitted to hospital. The situation was reversed with the control group; inspection of the adjusted residuals found a significantly greater proportion (71.4\%) of those control group members who failed to attend follow-up were admitted to hospital.

\section{(2) The number of people within each group with one or more 'community episode(s)'. A} decision was made to count a person as having suffered a 'community episode' if they received 25 or more community sessions within a year. This was considered by us to be in excess of the usual number of times a person would be seen by a case manager in the Victorian mental health system within that time frame. The mean number of community contacts for the study sample of $N=80$ was 13.72 . It was found that $75 \%$ $(60 / 80)$ of the sample had less than 25 contact days in the community. We acknowledge overtly that this constitutes a crude calculation but provides some index of what might be considered to constitute a 'relapse in the community'.

Using this criterion, statistical analyses found no significant result for attender status with $\chi^{2}(2)=1.26$, exact $p=.57$, but there was a strong trend for 1 -year non-attender status, with $\chi^{2}(2)=5.90$, exact $p=.06$. Inspection of the adjusted residuals found that non-attenders in the control group were significantly more likely to suffer community episodes $(57 \%)$ than would be expected by chance. 
(3) The number of people within each group with in-patient admission(s) and 'community episode(s)' combined. When people with in-patient admissions and/or community episodes were combined, there was no effect for attender status across the three groups with $\chi^{2}(2)=2.08$, exact $p=.37$. However, there was a strong trend towards significance for non-attender status with $\chi^{2}(2)=5.93$, exact $p=.06$. To amplify, inspection of the adjusted residuals found a significantly lower proportion (i.e. 16.7\%) of those in the refusal group who failed to attend the 1-year follow-up, were likely to be admitted to hospital or suffer a 'community episode'. For the control group, the situation was reversed. Inspection of the adjusted residuals identified a significantly greater proportion $(71.4 \%$ ) of those control group members who failed to attend followup, were admitted to hospital or suffered a 'community episode'.

Adopting a different tack, in examining for differences across the groups in terms of the total number of admissions and episodes (as opposed to the number of people with one or more admissions and/or episodes), we found no differences between the three groups (Kruskal-Wallis, $p=.52$ ).

(4) The time taken to first in-patient admission following the end-of-treatment assessment for each of the three groups. A Kaplan-Meier survival analysis was performed to assess the length of time taken by each of the three groups to first in-patient admission. There were no significant differences in the survival times as indicated by the log rank test (log rank statistic $(2)=1.47, p=.48)$.

Table 3. Numbers of individuals with in-patient admissions and community episodes displayed according to group and attender status

\begin{tabular}{lcccc}
\hline $\begin{array}{l}\text { Groups and } \\
\text { attender status }\end{array}$ & $\begin{array}{c}\text { Number of } \\
\text { people in the } \\
\text { group }\end{array}$ & $\begin{array}{c}\text { Number of } \\
\text { people with one } \\
\text { or more in- } \\
\text { patient }\end{array}$ & $\begin{array}{c}\text { Number of } \\
\text { people with one } \\
\text { or more } \\
\text { community } \\
\text { admission(s) }\end{array}$ & $\begin{array}{c}\text { Total number of } \\
\text { people with } \\
\text { in-patient } \\
\text { admission(s) and/ } \\
\text { or community } \\
\text { episode(s) }\end{array}$ \\
\hline
\end{tabular}

COPE

$\begin{array}{lcccc}\text { Attender } & 34 & 12 & 10 & 17 \\ \begin{array}{l}\text { Non-attender } \\ \text { Refusal }\end{array} & 10 & 4 & 2 & 5 \\ \text { Attender } & 9 & 3 & 1 & 3 \\ \quad \text { Non-attender } & 12 & 2 & 1 & 2 \\ \text { Control } & & 1 & 2 & 2 \\ \text { Attender } & 8 & 5 & 4 & 5 \\ \text { Non-attender } & 7 & 5\end{array}$

Note. The final column does not represent the simple addition of patients with in-patient admissions (Column 2) and patients with 'community episodes' (Column 3). This is because patients may have had one or more in-patient admission(s) and one or more 'community episode(s)'. 
Number of COPE sessions received. Pearson's correlations were run to ascertain the relationship between the number of sessions received by a patient and their scores on the I/SO, EM, BPRS, SANS, BDI, GSI, and the QLS at 1-year follow-up. With the exception of the QLS, partial correlations were conducted controlling for pre-treatment scores on the specific measure of interest. There were no significant relationships at all, with the correlations ranging from $r$ s of -.02 to .20 .

\section{Discussion and conclusions}

Inspection of the between-group results at follow-up reveals that COPE significantly outperformed the control group but only on the I/SO. This latter result might suggest that COPE impacts most on insight and attitudes towards treatment although the issue of optimal adaptation and its time course is a complex one (McGorry \& McConville, 1999). The lack of obvious differences between groups on the BPRS is not a problem for the study. This was not the focus of our treatment: our patients are a first-episode group who evinced low levels of positive symptoms at baseline and continued to do so at the two subsequent assessment points. Moreover, this is a neuroleptic treatment-responsive treatment group (McGorry et al., 1996; Power et al., 1998). The apparent lack of differences on the EM, SANS, BDI, GSI and QLS measures is disappointing.

The refusal group, and to a lesser extent, the control group, outperformed the COPE group on the GSI measure of the SCL-90-R, and especially the BDI, according to the mean scores displayed in Table 2. Yet, as was reported in Jackson et al. (1998), the BDI and SCL-90-R scores were not high at pre-treatment and end-of-treatment, and this was true for follow-up. In fact, for the follow-up attender only analyses, and with the exception of the refusal group at the follow-up assessment, the BDI scores decreased over time and were lower at end-of-treatment and follow up for the three groups (see Table 2 ). So, the mean BDI score of the COPE group did not worsen, but it did not reduce down to the respective mean levels of the other two groups. Nevertheless, the mean follow-up BDI score of 6.33 for the COPE group would not seem to be clinically significant. In fact, for the BDI and GSI measures, norms exist. As regards the BDI, Beck and Beck (1972) found that non-depressed patients obtained a mean of 4.73 $(\mathrm{SD}=4.73)$ whilst mildly depressed patients received a mean of $9.37(\mathrm{SD}=5.71)$. Table 2 indicates that at no point did any of the three groups (including the COPE group) exceed the mean levels for the mean levels for the mildly depressed patients. Derogatis (1983) supplied mean GSI scores (and SDs) for four groups: non-patients, $M=0.31(\mathrm{SD}=0.31)$; adolescent non-patients, $M=0.76(\mathrm{SD}=0.54)$; psychiatric outpatients, $M=1.26$ ( $\mathrm{SD}=0.68)$; and psychiatric in-patients, $M=1.30(\mathrm{SD}=0.82)$. Table 2 shows that the scores of the three groups fell above the scores for the nonpatients, and mostly around or below the scores for the adolescent non-patients.

On most measures, there was maintenance of end-of-treatment levels at 1-year followup for the three groups, except for some deterioration on the BPRS for the COPE group $(p=.03)$ and some evidence of deterioration on the QLS $(p=.06)$ and $\operatorname{EM}(p=.09)$ measures for the refusal group. Table 2 shows that the refusal group actually deteriorated further than the COPE group on the BPRS but the non-significant result could be due to the small number of patients who completed in the refusal group (nearly four times smaller than the COPE group). 
There were no differences in terms of the relapse indices (i.e. number of people with hospital re-admissions, number of people with 'community episodes', and both combined) between the three groups. Neither was there any difference between the three groups in the time taken to relapse (again defined in terms of in-patient re-admissions). These results are disappointing but must be considered important, especially the results for in-patient re-admissions, as this is a categorical variable (i.e. admitted vs. not admitted) unlike the arguably contentious way we determined 'community episodes'. Importantly, whereas the clinical measures could only be conducted on 51 patients who completed the 1-year assessment, data on in-patient admissions and community episodes could be collected for the entire 80 patients who participated in the original COPE study (Jackson et al., 1998). Although there were differential effects between participants and non-participants within the two comparison groups, there was not within the COPE group, so it could not be argued that COPE participants had more relapses than the COPE non-participants. Also disappointing was the finding that the number of COPE sessions received by a patient did not seem an important factor in outcome. Possibly, it is both the use that the client makes of the session, and the focus of the session, that is of far more importance in influencing outcomes.

There were a number of methodological problems that bedevilled the study. The first was the small number of patients left at follow-up in the refusal and control groups. This reduced power in the analyses, making it difficult to detect differences between COPE and the two comparison groups at the .05 level. Also, there was far more power to detect significant differences across the follow-up period (i.e. from the end-of-treatment to the 1-year follow-up assessment) within COPE than within each of the two comparison groups, given the greater number of patients in the COPE group. It is a distinct possibility that significant within-group differences may have emerged between the end-of-treatment and follow-up assessments with both larger cell sizes and the retention of greater numbers in the two comparison groups.

A second related problem concerns the effects of the differential loss of patients from each of the three groups. Examination of differences between the scores of the follow-up attenders and the non-attenders (as assessed at pre-treatment and at the end of treatment) indicates that the absence of a proportion of patients from within the control group (i.e. the follow-up non-attenders) may have 'boosted' the follow-up scores of the control group. This, taken in turn with the generally poorer performance of the attenders in the COPE group, may have had the effect of mitigating the effects of COPE at follow-up in the COPE group/control group comparisons. Of course, this is based on the assumption that non-attenders, at least in the two comparison groups, would have continued on at follow-up with scores no better than, or worse than, their pre-treatment and, especially, their end-of-treatment, levels.

An important goal of conducting this trial was to determine whether the treatment approach would require modifications in our second study, which is a randomized, controlled trial (RCT). From the current pilot study we concluded that COPE therapy needed to be further standardized - therefore, we insisted on stricter adherence to the COPE manual. Our individual and group supervision process reinforced this. In addition, we introduced a phase-oriented approach to therapy in the RCT in order to keep both the therapist and supervisor focused on the COPE agenda. We wanted to avoid patients becoming 'stuck' in the engagement and assessment phases and help them 
focus on issues pertaining to adaptation and secondary morbidity. This RCT is now being completed and we will report our findings in a subsequent paper.

\section{Acknowledgements}

The Early Psychosis Research Program has been funded by a generous 8-year program grant from the Victorian Health Promotion Foundation. The authors would like to acknowledge the important contributions of Christina Curry, Kathryn Elkins, Cathrine Mihalopoulos, and Colleen McFarlane for the detailed assessments of patients that they undertook.

\section{References}

American Psychiatric Association (1987). Diagnostic and statistical manual of mental disorders (3rd rev.) (DSM-III-R). Washington, DC: APA.

Andreasen, N. C. (1983). Schedule for the assessment of negative symptoms. Iowa City, IA: University of Iowa. Beck, A. T., \& Beck, R. W. (1972). Screening depressed patients in family practice: A rapid technique. Postgraduate Medicine, 52, 81-85.

Bentall, R. P., Haddock, G., \& Slade, P. D. (1994). Cognitive behavior therapy for persistent auditory hallucinations: From theory to therapy. Behavior Therapy, 25, 51-66.

Burgess, P. M., Joyce, C. M., Pattison, P. E., \& Finch, S. J. (1992). Social indicators and the prediction of psychiatric inpatient service utilisation. Social Psychiatry and Psychiatric Epidemiology, 27, 83-94.

Chadwick, P., \& Birchwood, M. (1994). The omnipotence of voices: A cognitive approach to auditory hallucinations. British Journal of Psychiatry, 164, 190-201.

Chadwick, P. J., Birchwood, M., \& Trower, P. (1996). Cognitive therapy for delusions, voices and paranoia. Chichester: Wiley.

Chanen, A. (1987). Attitudes and recovery style in recent onset psychosis. Unpublished thesis. Department of Psychological Medicine, Monash University, Victoria, Australia.

Derogatis, L. R. (1977). SCL-90-R: Administration, scoring and procedures manual. Towson, MD: Clinical Psychometric Research.

Derogatis, L. R. (1983). SCL-90-R: Administration, scoring and procedures manual - II for the R(evised) Version. Towson, MD: Clinical Psychometric Research.

Drury, V., Birchwood, M., Cochrane, R., \& Macmillan, F. (1996). Cognitive therapy and recovery from acute psychosis: A controlled trial: Impact on psychotic symptoms. British Journal of Psychiatry, 169, 593-607.

Edwards, J., Maude, D., McGorry, P. D., Harrigan, S. M. \& Cocks, J. (1998). Prolonged recovery in firstepisode psychosis. British Journal of Psychiatry, 172 (Supplement 33), 107-116.

Fowler, D., Garety, P., \& Kuipers, E. (1995). Cognitive behaviour therapy for psychosis: theory and practice. Chichester: Wiley.

Garety, P., Fowler, D., Kuipers, E., Freeman, D., Dunn, G., Bebbington, P., Hadley, C., \& Jones, S. (1997). London-East Anglia randomised controlled trial of cognitive-behavioural therapy for psychosis. II: Predictors of outcome. British Journal of Psychiatry, 171, 319-327.

Heinrichs, D. W., Hanlon, T. E., \& Carpenter, W. T. Jr. (1984) The Quality of Life Scale: An instrument for rating the schizophrenic deficit syndrome. Schizophrenia Bulletin, 10, 389-398.

Jackson, H. J., Edwards, J., Hulbert, C., \& McGorry, P. D. (1999). Recovery from psychosis: Psychological interventions. In P. D. McGorry \& H. J. Jackson (Eds), Recognition and management of early psychosis: A preventive approach (pp. 265-307). Cambridge: Cambridge University Press.

Jackson, H. J., McGorry, P. D., Edwards, J., \& Hulbert, C. (1996). Cognitively oriented psychotherapy for early psychosis (COPE). In P. Cotton and H. J. Jackson (Eds.), Early intervention and prevention in mental health (pp. 131-154). Melbourne: Australian Psychological Society.

Jackson, H., McGorry, P., Edwards, J., Hulbert, C., Henry, L., Francey, S., Maude, D., Cocks, J., Power, P., Harrigan, S., \& Dudgeon, P. (1998). Cognitively-oriented psychotherapy for early psychosis (COPE). Preliminary results. British Journal of Psychiatry, 172 (Supplement 33), 93-100.

Kingdon, D. G., \& Turkington, D. (1994). Cognitive-behavioral therapy of schizophrenia. New York: Guilford Press. 
Kleinman, A. (1980). Patients and healers in the context of culture. An exploration of the borderline between anthropology, medicine, and psychiatry. Berkeley, CA. University of California Press.

Kuipers, E., Garety, P., Fowler, D., Dunn, G., Bebbington, P., Freeman, D., \& Hadley, C. (1997). London-East Anglia randomised controlled trial of cognitive-behavioural therapy for psychosis. I: Effects of the treatment phase. British Journal of Psychiatry, 171, 319-327.

Lieberman, J., Jody, D., Geisler, S., Alvir, J., Loebel, A., Szymanski, S., Woerner, M., \& Borenstein, M. (1993). Time course and biologic correlates of treatment response in first-episode schizophrenia. Archives of General Psychiatry, 50, 369-376.

McGlashan, T. H., Wadeson, H. S., \& Carpenter, W. T. (1977). Recovery style from psychosis. Journal of Nervous and Mental Disease, 164, 182-190.

McGorry, P. D., Copolov, D. L., \& Singh, B. S. (1990). Royal Park Multidiagnostic Instrument for Psychosis: Rationale and review. Schizophrenia Bulletin, 16, 501-515.

McGorry, P. D., Copolov, D. L., Singh, B. S., Kaplan, I., Dossetor, C. R., \& van Riel, R. J. (1990). Royal Park Multidiagnostic Instrument for Psychosis: Development, reliability and validity. Schizophrenia Bulletin, 16, 517-536.

McGorry, P. D., Edwards, J., Mihalopoulos, C., Harrigan, S. M., \& Jackson, H. J. (1996). EPPIC: An evolving system of early detection and optimal management. Schizophrenia Bulletin, 22, 305-326.

McGorry, P. D., Goodwin, R. J., \& Stuart, G. W. (1988). The development, use, and reliability of the BPRS (Nursing Modification): An assessment procedure for the nursing team in clinical and research settings. Comprehensize Psychiatry, 29, 575-587.

McGorry, P. D., \& McConville, S. (1999). Insight in psychosis: An elusive target. Comprehensive Psychiatry, 40, 131-142.

Nathan, P. E., \& Gorman, J. M. (Eds) (1998). A guide to treatments that work. New York: Oxford University Press.

Overall, J. E., \& Gorham, D. R. (1962). The brief psychiatric rating scale. Psychological Reports, 10, 799812.

Power, P., Elkins, K., Adlard, S., Curry, C., McGorry, P., \& Harrigan, S. (1998). Analysis of the initial treatment phase in first-episode psychosis. British Journal of Psychiatry, 172 (Supplement 33), 71-76.

Roth, A., \& Fonagy, P., with contributions from Parry, P., Target, M., \& Woods, P. (1996). What works for whom? A critical review of psychotheraty research. New York: Guilford Press.

Tarrier, N. (1992). Management and modification of residual positive psychotic symptoms. In M. J. Birchwood \& N. Tarrier (Eds.), Innovations in psychological management of schizophrenia: Assessment, treatment and services (pp. 147-169). Chichester: Wiley.

Tarrier, N., Yusupoff, L., Kinney, C., McCarthy, E., Gledhill, A., Haddock, G., \& Morris, J. (1998). Randomised controlled trial of intensive cognitive behaviour therapy for patients with chronic schizophrenia. British Medical Journal, 317, 303-307. 